\title{
АНАЛИЗ ИСПОЛЬЗОВАНИЯ САRNЕТ TIR В СИСТЕМЕ СТРАХОВАНИЯ ГРАЖДАНСКОЙ ОТВЕТСТВЕННОСТИ В РЕСПУБЛИКЕ БЕЛАРУСЬ
}

\section{(C) 2019 Киевич Александр Владимирович}

доктор экономичсеких наук, профессор кафедры финансов

Полесский государственный университет 225710, Республика Беларусь, г. Пинск

E-mail:a.v.kievich@yandex.ru

\section{(c) 2019 Пригодич Ирина Александровна}

кандидат экономических наук, доцент кафедры финансов

Полесский государственный университет

225710, Республика Беларусь, г. Пинск

E-mail: prigodich.ira@yandex.by

\section{(c) 2019 Конончук Ирина Анатольевна}

кандидат экономических наук, доцент кафедры финансов

Полесский государственный университет

225710, Республика Беларусь, г. Пинск

E-mail: i_kononchuk@mail.ru

Особенность страхования гражданской ответственности перед таможенными органами с применением Carnet TIR заключается в том, что оно покрывает ответственность перед таможенными органами по обязательствам, которые возникают при причинении ущерба страхователем. Названная ответственность вытекает из использования в системе международной гарантийной цепи каждой отдельной книжки МДП, которая предоставляется в период действия страхового полиса. Статья посвящена исследованию её организации в Республике Беларусь и динамике развития в стране по данным за 3 года.

Ключевые слова: Carnet TIR, грузоперевозки, таможня, граница, страхование, ответственность.

«Таможенная конвенция о международной перевозке грузов с применением книжки МДП (международных дорожных перевозок)» определяет перевозки грузов, осуществляемые без их промежуточной перегрузки в дорожных транспортных средствах, их составах или контейнерах, с пересечением одной или нескольких границ от таможни места отправления до таможни места назначения, при условии, что определенная часть операции МДП между её началом и концом производится автомобильным транспортом. Товары, перевозимые по процедуре МДП, освобождаются как от уплаты в промежуточных таможнях ввозных и вывозных пошлин и налогов, так и от их депонирования. Кроме того, данные товары не подлежат процедуре таможенного досмотра в указанных таможнях, а сбор за таможенное оформление книжек МДП (Carnet TIR) в этих таможнях не взимается. Такая ситуация в очередной раз подтверждает государственную политику множественности различных налоговых льгот и преференций, направленных на раз- витие страхового рынка в Республике Беларусь, включая его развитие во внешнеэкономической деятельности страны [1].

Общие правила применения системы МДП заключаются в том, что таможни отправления должны находиться в одной стране, таможни назначения - не более чем в двух странах, а их общее количество не должно превышать четырёх.

Перевозка товаров по системе МДП осуществляется при соблюдении следующих условий:

1) оформления книжки МДП - контрольного документа, выдаваемого и правильно оформляемого в стране отправления и сопровождающего товар;

2) наличия международной гарантии. Гарантирующее объединение на весь период перевозки выдает гарантию при наступлении момента уплаты пошлин и сборов;

3) допуска дорожных транспортных средств, их составов или контейнеров для перевозки под таможенными печатями и пломбами. На транспортных средствах должны быть закре- 
плены прямоугольные съёмные таблички «TIR»;

4) признания мер таможенного контроля, принимаемых в государстве отправления, достаточными в государствах транзита и назначения.

Система МДП подразумевает использование Carnet TIR (книжки МДП) - это документ таможенного транзита, который предоставляет право перевозки грузов через границы стран в опломбированных таможней кузовах автомобилей (контейнерах) с упрощением таможенных процедур и выдается Белорусской ассоциацией международных автомобильных перевозчиков (БАМАП).

Белорусская ассоциация международных автоперевозчиков, выдавая книжки МДП, несет ответственность перед Международной ассоциацией и её членами за соблюдение белорусскими членами ассоциации требований Конвенции МДП и в частности за уплату сумм, связанных с нарушениями этих требований. Поэтому в качестве обеспечения при выдаче книжек МДП Белорусская ассоциация принимает три вида гарантий:

1) депонирование суммы в размере максимальной ответственности, которую может нести перевозчик в результате нарушения требований Конвенции МДП;

2) гарантию банка на необходимую сумму;

3) страховой полис, покрывающий все риски, возникающие при осуществлении операции МДП, не зависимо от характера неблагоприятного события, однако условия полиса в обязательном порядке должны соответствовать требованиям Международной ассоциации автоперевозчиков, которая рекомендует страховой полис как наиболее приемлемую форму обеспечения [2].

Осуществлять перевозку по процедуре МДП имеет право держатель carnet TIR - предприятие-резидент, оказывающее услуги по перевозке грузов в международном сообщении, функционирующее на территории страны не менее полугода и являющееся членом БАМАП.

На каждое транспортное средство или контейнер оформляется один Carnet TIR, который действителен только в течение одной перевозки. На грузоотправителя возлагается ответственность по оформлению данного таможенного документа в месте погрузки. Перевозчик либо его представитель в свою очередь проверяет правильность оформления Carnet TIR, заве- ряет его своей подписью на всех заполненных отрывных листах. Таким образом, перевозчик подтверждает достоверность сведений о грузе. После завершения перевозки Carnet TIR с соответствующими отметками таможни назначения или таможни вывоза возвращается перевозчику и служит подтверждением надлежащего завершения процедуры МДП.

По правилам страхования ответственности автоперевозчика перед таможенными органами объектом страхования являются имущественные интересы страхователей, связанные с выполнением ими операций МДП.

Международный союз автомобильного транспорта (МСАТ) разработал Специальные условия страхования МДП, которые в обязательном порядке включаются в полис национальных страховщиков.

Страхователями являются юридические лица и индивидуальные предприниматели, которые осуществляют международные перевозки грузов с применением Carnet TIR.

На страхование принимаются:

1) гражданская ответственность страхователя перед таможенными органами в системе международной гарантийной цепи по уплате причитающихся ввозных и вывозных пошлин и сборов, включая проценты за просрочку платежей;

2) убытки, связанные с предотвращением или уменьшением размера ущерба вследствие случайного повреждения таможенных печатей и пломб, необходимостью перегрузки груза на другое транспортное средство, полным или частичным уничтожением груза;

3) расходыпо расследованию обстоятельств и защите интересов страхователя в судебных и арбитражных органах по происшествиям, ответственность, за которые возлагается на страхователя.

Не страхуется только ответственность перед таможенными органами при использовании страхователями TIR «Табак - алкоголь».

Лимит ответственности отличается в различных странах (табл. 1). В РБ он установлен в размере 50000 долларов США на каждый Carnet TIR.

Размер страхового взноса устанавливается в твёрдой сумме за каждый Carnet TIR, но определяется индивидуально для каждого страхователя на основе информации, указанной в заявлении на страхование. Расчёт суммы страхового взно- 
Таблица 1. Перечень Гарантийных лимитов ответственности

\begin{tabular}{|c|c|c|c|}
\hline Ассоциация & Страна & Валюта & Предел гарантии в валюте \\
\hline FEBETRA* & BEL & EUR & 60000 \\
\hline FEBETRA* & LUX & EUR & 60000 \\
\hline ASTAG* & CHE & CHF & 100000 \\
\hline BGL* & $\overline{\mathrm{DEU}}$ & EUR & 60000 \\
\hline DTL* & DNK & EUR & 60000 \\
\hline AFTRI & FRA & EUR & 60000 \\
\hline SKAL* & FIN & EUR & 60000 \\
\hline RHA* & GBR & EUR & 60000 \\
\hline FTA* & GBR & EUR & 60000 \\
\hline IRHA* & IRL & EUR & 60000 \\
\hline NLF & NOR & USD & 50000 \\
\hline SCT/TLN* & NLD & EUR & 60000 \\
\hline $\mathrm{KNV}^{*}$ & NLD & EUR & 60000 \\
\hline EVO/SIEV* & NLD & EUR & 60000 \\
\hline $\mathrm{SA}^{*}$ & SWE & EUR & 60000 \\
\hline ERAA* $^{*}$ & EST & EUR & 60000 \\
\hline LINAVA* & LTU & EUR & 60000 \\
\hline LA* $^{*}$ & LVA & EUR & 60000 \\
\hline BAIRC & BLR & USD & 50000 \\
\hline TDA* & CYP & EUR & 60000 \\
\hline ASTIC* & ESP & EUR & 60000 \\
\hline OFAE* $^{*}$ & GRC & EUR & 60000 \\
\hline UICCIAA* & ITA & EUR & 60000 \\
\hline CESMAD SLOVAKIA* & SVK & EUR & 60000 \\
\hline ANTRAM* $^{*}$ & PRT & EUR & 60000 \\
\hline UCCIMCCE & TUR & USD & 50000 \\
\hline GIZ INTERTRANSPORT** & SVN & EUR & 60000 \\
\hline ANALTIR & ALB & USD & 50000 \\
\hline AEBTRI & BGR & USD & 50000 \\
\hline CESMAD BOHEMIA* & CZE & EUR & 60000 \\
\hline AIST* & $\overline{D E U}$ & EUR & 60000 \\
\hline ATRH* $^{*}$ & HUN & EUR & 60000 \\
\hline UNTRR & ROU & USD & 50000 \\
\hline ZMPD* & POL & EUR & 60000 \\
\hline ARTRI & ROU & USD & 50000 \\
\hline ASMAP & RUS & USD & 50000 \\
\hline GIRCA & CEO & USD & 50000 \\
\hline IRTB & ISR & USD & 50000 \\
\hline ICCIM & IRN & USD & 50000 \\
\hline AITA & MDA & USD & 50000 \\
\hline KATC & KWT & USD & 50000 \\
\hline CCIT & TUN & USD & 50000 \\
\hline TRANSPORTKOMERC & HRV & USD & 50000 \\
\hline AMERIT & MKD & USD & 50000 \\
\hline AIRCU & UKR & USD & 50000 \\
\hline AIRCUZ & UZB & USD & 50000 \\
\hline
\end{tabular}




\begin{tabular}{|c|c|c|c|}
\hline ABADA & AZE & USD & 50000 \\
\hline THADA & TKM & USD & 50000 \\
\hline ABBAT & TJK & USD & 50000 \\
\hline AIRCA & ARM & USD & 50000 \\
\hline KYRGYZAIA & KGZ & USD & 50000 \\
\hline KAZATO & KAZ & USD & 50000 \\
\hline CCIAB & LBN & USD & 50000 \\
\hline SNC ICC & SYR & USD & 50000 \\
\hline AISO* & AUT & EUR & 60000 \\
\hline AMTRI & MAR & USD & 50000 \\
\hline RACJ & JOR & USD & 50000 \\
\hline NARTAM & MNG & USD & 50000 \\
\hline CCIS-ATT & SCG & USD & 50000 \\
\hline ATTO* & MLT & & 60000 \\
\hline
\end{tabular}

* Национальные ассоциации Европейского Союза

са осуществляется на базе количества Carnet TIR, которое планирует приобрести перевозчик в течение срока действия страхового полиса. В конце периода страхования производится перерасчёт суммы страхового взноса с учётом фактического количества приобретенных Carnet TIR. Уплата взноса может производиться в любой валюте по курсу НБ РБ на день его уплаты.

Страховой взнос может уплачиваться двумя способами: единовременно и по частям (в рассрочку).

Первый способ применяется в случае, когда количество Carnet TIR по первой заявке равно количеству Carnet TIR, предлагаемых на страхование, а второй - когда количество Carnet TIR по первой заявке меньше количества Carnet TIR, предлагаемых на страхование.

Страховой полис подписывается страхователем и страховщиком, к нему в обязательном порядке прилагается заявка на Carnet TIR, которые страхователь намеревается получить в БАМАП в течение срока действия полиса.

Период ответственности страховщика по договору страхования совпадает с оговоренным в страховом полисе сроком действия договора. Если срок действия Carnet TIR истекает или операция МДП завершается позже периода страхования, то ответственность страховщика распространяется на весь период действия Carnet TIR или до завершения операции МДП, при условии, чтo Carnet TIR выдана или операция МДП начата в течение установленного в страховом полисе периода страхования.

Страховое покрытие, требуемое МСАТ, яв- ляется больше гарантийным, т.е. перевозчик, оплативший страховую премию, не является выгодоприобретателем по договору страхования. Выгодоприобретателем (получателем страхового возмещения) в данном случае выступает национальное объединение, находящееся в стране, где имело место нарушение процедуры МдП.

Механизм выплаты страхового возмещения активизируется только в случае, если таможенные органы не имеют возможности востребовать таможенные пошлины и сборы у непосредственных нарушителей процедуры МДП или перевозчиков-держателей Carnet TIR.

Страховым случаем является факт признания и оплаты МСАТ претензии, предъявленной таможенными органами международной гарантийной цепи в связи с нарушением процедуры, предусмотренной Конвенцией МДП, и неисполнением перевозчиком своих обязательств в соответствии с Декларацией.

Страхованием не покрывается ответственность перед таможенными органами, возникшая в результате: нарушения страхователем или его служащими операций или процедуры перевозки грузов с применением Carnet TIR, включая их предоставление другому перевозчику; перевозок особо ценных грузов, к которым относятся слитки драгоценных металлов, драгоценные камни, банкноты, монеты, дорожные и банковские чеки, облигации, платёжные средства, ценные бумаги иного рода и грузы, для перевозок которых требуется получение специальных транзитных таможенных документов, кроме Carnet TIR; перевозки грузов, но не свя- 
занной с нарушением операций или процедуры перевозки с применением Carnet TIR.

Договор страхования заключается на срок до 1 года. Ответственность страховщика по договору страхования распространяется на операции МДП в течение установленных сроков действия Carnet TIR в рамках оговоренного в страховом полисе срока страхования. Она начинается с момента оформления книжки МДП в таможне места отправления и заканчивается в момент оформления её в таможне места назначения. Обе стороны договора страхования: страхователь и страховщик имеют право на расторжение страхового договора. При этом страховой взнос страхователю возвращаться полностью или частично, либо не возвращаться вообще. Это зависит от причины расторжения страхового договоpa.

В случае существенного изменения обстоятельств, которые стороны учитывали при заключении договора страхования, страховщик вправе инициировать изменения условий договора страхования. Если страхователь возражает против изменения условий договора страхования, то договор расторгается, а страховщик возвращает страхователю страховую премию по неиспользованным Carnet TIR за вычетом понесённых расходов. Возврат производится в безналичном порядке в течение 10 рабочих дней со дня получения страховщиком по его запросу письменного подтверждения БАМАП.

Договор страхования действует только на территории, направлении или в рамках маршрута перевозки, указанных в страховом полисе.

Страхователь в установленный срок обязан информировать страховщика о наступлении любого события или происшествия, последствия которых могут служить основанием для возникновения страхового случая и предъявления требований по выплате страхового возмещения, а также незамедлительно извещать об этом БАМАП. Под названными событиями подразумеваются: утеря, хищение или повреждение Carnet TIR; наличие оговорок на корешках Carnet TIR; неоформление Carnet TIR таможенными органами при выезде из страны, транзите или в месте назначения; нарушения выполнения транспортной перевозки по причине дорожно-транспортного происшествия и т.д.

Наступление перечисленных и некоторых иных событий требует от страхователя принятия всех возможных мер по предотвращению и уменьшению последствий происшествия с целью минимизации размера причинённого ущерба. Если ответственность страхователя возникает по вине третьих лиц, то он должен предпринять всевозможные меры для документального закрепления своих прав требования к этим лицам при предъявлении в последствии регрессного иска. Выплата страхового возмещения производится не страхователю, а МСАТ в размере суммы, предварительно оплаченной МСАТ после рассмотрения дела таможенными органами. По данной причине такие выплаты рассматриваются как суммы возмещения, причитающиеся заинтересованным таможенным органам соответствующих стран. Для выплаты страхового возмещения страховщик должен получить от МСАТ все необходимые документы, которые подтверждают факт страхового случая и размер ущерба: письменное извещение об убытке и претензии-требования таможенных органов о возмещении убытка. После получения всех необходимых документов страховщик в установленный срок составляет акт о страховом случае и выплачивает страховое возмещение [3].

Страхователь обязан уведомить страховщика обо всех возмещениях, полученных от других лиц, включая лиц, виновных в причинении ему вреда; от других страховых компаний в случае двойного страхования в отношении ущерба, покрываемого данным видом страхования. При наличии у страхователя доказательств, что при краже, грабеже, разбое он предпринял все необходимые меры безопасности и предосторожности, требуемые в данных обстоятельствах, то страховщик не реализует регрессное право к перевозчику. Если страхователь обладает доказательствами того, что ни он, ни лица, работающие в интересах страхователя по трудовым или гражданско-правовым договорам, не виновны и с их помощью был определен виновник ущерба, то право страховщика на регресс к перевозчику приостанавливается, а право требования к виновной стороне, прямо или косвенно причинившей ущерб переходит к страховщику. В случае невозможности доказательства виновности третьих сторон ответственность за удовлетворение регрессного требования возлагается на страхователя.

В Республике Беларусь только 3 страховые организации: БРУСП «Белгосстрах», БРУПЭИС «Белэксимгарант» и ЗАСО «ТАСК», осуществляют страхование ответственности перед таможен- 
ными органами с применением Carnet TIR. Активными участниками данной системы являются 67 стран и страны Европейского Союза.

Добровольное страхование гражданской ответственности перед таможенными органами согласно Таможенной конвенции о международной перевозке грузов с применением Carnet TIR в PБ регламентируют локальные нормативно-правовые документы страховых организаций, его осуществляющих, которые разработаны в соответствии с действующим национальным и международным законодательством:

1. Правила № 74 «Добровольное страхование гражданской ответственности перевозчика перед таможенными органами (согласно Таможенной конвенции о международной перевозке грузов с применением книжки МДП, 1975 г.)» (в ред. от 28.06.2016 № 635) - БРУСП «Белгосстрах»;

2. Правила № 8 «Добровольное страхование гражданской ответственности перевозчика перед таможенными органами (согласно Таможенной конвенции о международной перевозке грузов с применением книжки МДП, 1975 г.)»-

\section{БРУПЭИС «Белэксимгарант»;}

3. Правила № 23 «Добровольное страхование гражданской ответственности перевозчика перед таможенными органами» - ЗАСО «ТАСК» [4].

Основные условия, которые предлагают белорусские страховые организации в современных условиях по добровольному страхованию гражданской ответственности перед таможенными органами с применением Carnet TIR можно наглядно представить в табл. 2.

Основной страховой организацией на страховом рынке в целом и осуществляющей добровольное страхование гражданской ответственности перед таможенными органами с применением Carnet TIR, является БРУСП «Белгосстрах». В настоящее время, и, несмотря на положительную динамику развития страхового рынка в РБ, можно отметить отрицательный тренд по поступлениям сумм страховых премий по исследуемому виду страхования в стране, и в БРУСП «Белгосстрах» в частности. Страховые взносы по нему в 2015 году составили 912 299,70; в 2016 году - 729870,61 и в 2017 году - 378 977,98

Таблица 2. Различия по некоторым условиям страхования

\begin{tabular}{|c|c|c|c|}
\hline Показатель & БРУСП «Белгосстрах» & $3 \mathrm{ACO}$ «TACK» & $\begin{array}{c}\text { БРУПЭИС } \\
\text { «Белэксимгарант» }\end{array}$ \\
\hline $\begin{array}{c}\text { Лимит ответственности } \\
\text { (в отношении каждой } \\
\text { книжки МДП) }\end{array}$ & до 100000 Евро & до 50000 долларов США & $\begin{array}{c}\text { ограничен суммой, истре- } \\
\text { буемой таможенными } \\
\text { органами каждой страны } \\
\text { места нарушения тамо- } \\
\text { женной процедуры МдП }\end{array}$ \\
\hline $\begin{array}{c}\text { Годовой агрегатный } \\
\text { лимит ответственности } \\
\text { по всем книжкам МдП, } \\
\text { выданным Ассоциацией } \\
\text { за один календарный год }\end{array}$ & $\begin{array}{c}2000000 \text { швейцарских } \\
\text { франков }\end{array}$ & & $\begin{array}{c}20000000 \text { швейцарских } \\
\text { франков }\end{array}$ \\
\hline Срок страхования & от 1 дня до 1 года & от 1 дня до 1 года & от 1 дня до 1 года \\
\hline Базовый страховой тариф & $\begin{array}{l}\text { - в отношении 4-х ли- } \\
\text { стовых книжек МДП - } 3.3 \\
\text { дол. США; } \\
\text { - в отношении 6-ти ли- } \\
\text { стовых книжек МДП - } 3.3 \\
\text { дол. США; } \\
\text { - в отношении 14-ти } \\
\text { листовых книжек МДП - } \\
6.3 \text { дол. США; } \\
\text { - в отношении 20-ти } \\
\text { листовых книжек МДП - } \\
6.3 \text { дол. США. }\end{array}$ & $\begin{array}{c}10 \text { дол. США (на одну } \\
\text { книжку) }\end{array}$ & $\begin{array}{c}10 \text { дол. США } \\
\text { (на одну книжку) }\end{array}$ \\
\hline Дополнительные условия & & & $\begin{array}{c}\text { При уплате страхового } \\
\text { взноса в белорусских ру- } \\
\text { блях к базовому страхово- } \\
\text { му тарифу дополнительно } \\
\text { применяется корректиро- } \\
\text { вочный коэффициент } 1.3\end{array}$ \\
\hline
\end{tabular}


белорусских рублей.

Если рассматривать структуру страховых взносов, то можно отметить, что по исследуемому виду страхования они составили: в 2015 г. - 5,52\% от суммы страховых взносов по добровольным видам страхования БРУСП «Белгосстрах» и 5,35\% от общего объёма страховых взносов по всем видам страхования БРУСП «Белгосстрах»; в 2016 г.- 2,11\% от суммы страховых взносов по добровольным видам страхования БРУСП «Белгосстрах» и 2,09\% от общего объёма страховых взносов по всем видам страхования БРУСП «Белгосстрах»; в 2017 г.- 1,98\% от суммы страховых взносов по добровольным видам страхования БРУСП «Белгосстрах» и 1,92\% от общего объёма страховых взносов по всем видам страхования БРУСП «Белгосстрах». Примечательно, что страховые премии поступали лишь в Центральный аппарат БРУСП «Белгосстрах» [5].

Стоит также отметить, что помимо названных выше организаций, РУП «Белорусская национальная перестраховочная организация» также акцентирует внимание на необходимости развития добровольного страхования гражданской ответственности перед таможенными органами с применением Carnet TIR. Согласно бизнес-плана ее развития на 2018 год, основными положениями касательно исследуемого вида страхования являются:

1. Согласно договору квотного пропорционального перестрахования и ретроцессии гражданской ответственности перевозчика перед таможенными органами в рамках конвенции МДП 1975 года, государственное предприятие принимает в перестрахование 65\% ответственности по договору с последующим её размещением в размере $50 \%$ ответственности через брокера в синдикатах Lloyd's (Великобритания). В связи с решением MCAT с 1 октября 2012 г. «Miller Insurance Services LLP» (Великобритания) назначен брокером Lloyd's, ответственным за размещение Carnet TIR. Максимальный размер возмещения по каждому Carnet TIR по итогам 2017 года составлял 100000 Евро;

2. За 2017 год объём подписанной перестраховочной премии из-за рубежа составил 12022,9 тыс. рублей, или 108,3\% от плана на 2017 год (план - 11 100,0 тыс. рублей): при этом объем премии, переданной в ретроцессию, составил 39987,6 тыс. рублей, из которых зарубежным партнерам передано 33287,9 тыс. рублей, или $83,2 \%$, в том числе по страхованию ответствен- ности перед таможенными органами (МДП) 183,5 тыс. рублей.

Здесь необходимо обратить внимание на тот факт, что страховые организации РБ намерены повышать востребованность страхования гражданской ответственности перед таможенными органами с применением Carnet TIR и популяризировать его среди резидентов страны. В этой связи и РУП «Белорусская перестраховочная организация» обозначила некоторые задачи в данной сфере:

1. Перестрахование части гражданской ответственности по добровольному страхованию ответственности перевозчика перед таможенными органами в рамках Конвенции МДП 1975 года в объёме 172,5 тыс. рублей является одним из основных направлений стратегии деятельности государственного предприятия в 2018 г.;

2. Государственное предприятие передает в ретроцессию брокерской компании «Miller Insurance Services LLP» (Великобритания) 50\% ответственности по добровольному страхованию ответственности перевозчика перед таможенными органами в рамках Конвенции МДП 1975 г. По данному договору в 2018 г. государственное предприятие планирует передать 135 тыс. рублей зарубежным перестраховщикам;

3. Прогноз поступления перестраховочной премии: в бизнес-плане на 2018 г. предусмотрен темп роста начисленной перестраховочной премии в размере 110,5\% от начисленной в 2017 году, что составит 94300,0 тыс. рублей. Выполнение планируемого объема перестраховочного взноса предполагается достичь в частности и за счёт реализации договора перестрахования части ответственности по добровольному страхованию гражданской ответственности перевозчика перед таможенными органами в рамках Конвенции МДП 1975 года - 172,50 тыс. рублей. Осуществление поставленной задачи происходит в рамках мероприятий в области перестрахования в результате реализации договора квотного пропорционального перестрахования и ретроцессии гражданской ответственности перевозчика перед таможенными органами. В соответствии с данным договором государственное предприятие принимает в перестрахование риски гражданской ответственности перевозчика перед таможенными органами, застрахованные на условиях сострахования БРУСП «Белгосстрах» и БРУПЭИС «Белэксимгарант».

Подводя итог, можно отметить, что система 
МДП имеет явные преимущества для таможенных органов, поскольку сокращает число обычных требований, предусмотренных процедурами национального транзита. В то же время она позволяет избежать больших затрат времени и средств, физического досмотра в странах транзита, помимо осмотра печатей и пломб и внешнего состояния транспортных средств и контейнеров. Кроме того, операции международного транзита обеспечиваются лишь одним транзитным документом - Carnet TIR, что снижает возможность представления неточной информации таможенным органам.

Устраняя отчасти традиционно существующие препятствия на пути международных гру- зовых перевозок, система МДП содействует развитию международной торговли. Грузы могут пересекать национальные границы с минимальным вмешательством таможенных органов, что позволяет увеличить скорость доставки и значительно сократить транспортные расходы.

В настоящее время страховые организации страны принимают все необходимые меры по развитию страхования гражданской ответственности перед таможенными органами с применением Carnet TIR. Наращивание его объемов поспособствует развитию не только страхового рынка в стране, но и поддержанию статуса Республики Беларусь как экспортно-ориентированной страны на мировой арене.

\section{Библиографический список}

1. Киевич А. В. Основные тенденции и перспективы развития страхового рынка Республики Беларусь / А.В. Киевич // Современные аспекты экономики. 2017. № 4 (236). С. 76-85.

2. Страхование гражданской ответственности перевозчика перед таможенными органами [Электронный pесурс] / ЗАСО «ТАСК».- Режим доступа: https://task.by /corporate/responsibility/customs/.- Дата доступа: 20.12.2018 г.

3. Пригодич И.А. Подходы к определению сущности риска в различных теориях / И.А. Пригодич // Управление в социальных и экономических системах: материалы XXI Междунар. науч.-практ. конф. Редкол.: Н.В. Суша [и др.]. Минск. 2012. С. 102-104.

4. Конончук И.А. Реализация налоговой политики, стимулирующей страхование в Республике Беларусь // Экономика и банки. 2017. № 1. С.3-10.

5. Правила страхования [Электронный ресурс] / БРУСП «Белгосстрах».- Режим доступа: http://bgs.by/ eventinsurance/12514/.- Дата доступа: 10.12.2018 г. 